\title{
Disputa de poder ou disputa por prestígio com o Brasil na política externa de Menem? A visão da diplomacia
}

\author{
Dispute over power or dispute over prestige with Brazil in Menem's foreign policy? The vision of diplomacy
}

DOI: https://doi.org/10.22456/2178-8839.102611

Ariane Costa dos Santos

Fundação Getúlio Vargas, Rio de Janeiro, Brasil ariane1804@hotmail.com

Miriam Gomes Saraiva Universidade do Estado do Rio de Janeiro, Rio de Janeiro, Brasil miriamgsaraiva@gmail.com

\begin{abstract}
Resumo
É uma afirmativa frequente na literatura dos estudiosos da política externa argentina de que os comportamentos da Argentina frente ao Brasil e aos Estados Unidos teriam tido vínculos, pesos e contrapesos, ou impactos um no outro. Com vistas a dialogar com essa literatura, o objetivo deste artigo é analisar os bastidores da política externa argentina e identificar o que esteve por detrás dos desentendimentos político-diplomáticos do governo Menem com o Brasil. Dessa forma, é destacado aqui o papel da percepção diplomática da Argentina na definição da sua estratégia junto ao seu vizinho e sócio fundador do MERCOSUL. Com o intuito de atribuir uma dimensão empírica à resposta, são destacados dois episódios ilustrativos das principais divergências entre os dois países entre 1997 e 1999: i) obtenção do status de aliado especial extra-OTAN por parte da Argentina, em 1997, com consequente reação negativa por parte do Brasil; ii) oposição da Argentina ao pleito brasileiro por uma cadeira permanente no Conselho de Segurança das Nações Unidas, tema caro à diplomacia brasileira e que suscitou reações negativas das autoridades argentinas. Para atender aos objetivos colocados, as fontes foram concentradas em entrevistas realizadas com diplomatas brasileiros e argentinos, além de discursos de autoridades e matérias de imprensa.
\end{abstract}

Palavras-chave: Política externa argentina; Governo Menem; Diplomacy.

\begin{abstract}
It is a usual statement among foreign policy experts that Argentine policy to Brazil and the United States has established ties, checks and balances, besides impacts on one another. To dialogue with this literature, this article aims to analyze the backstage of argentine's foreign policy, as well as to identify the reasoning behind Menem's government political-diplomatic disagreements towards Brazil. In this context we highlight the diplomatic perception in the realm of the best strategy to deal along with its neighbor and Mercosur's founding partner. For an empirical approach, we focus on two different disagreement episodes between those two countries between 1997 and 1999: i) the designation of major non-NATO ally given by the US government to Argentine, in 1997, resulting on a negative Brazilian reaction; and ii) the Argentine opposition to the Brazilian plea for a permanent seat at the United Nations Security Council, a relevant subject to the Brazilian diplomacy by the time, which was met by fierce negative reactions from Argentinean authorities. To fulfill the above-mentioned objectives our sources are focused on semi-structured interviews with Brazilian and Argentine diplomats, besides authorities' speeches and press reports.
\end{abstract}

Keywords: Argentine foreign policy; Menem government; Diplomacy. 


\section{Introdução}

O ano de 1999 foi um ano difícil nas relações bilaterais entre Brasil e Argentina. Teria sido o ano mais difícil com a desvalorização do Real seguida de emissão da resolução 911 por parte da Argentina ${ }^{1}$, e com o consequente aumento das desconfianças no campo político. A partir de 1999, o próprio MERCOSUL perde sua dinâmica devido ao esgotamento do modelo de comércio praticado somado às ondas protecionistas decorrentes da crise cambial brasileira. No entanto, os desacordos não se resumiram ao campo econômico; também se fizeram presentes na dimensão político-diplomática e, de alguma forma, se entrelaçaram com o comportamento da Argentina frente aos Estados Unidos.

O objetivo deste artigo é identificar, no campo das ideias, o que esteve por detrás dos desentendimentos do governo argentino com o Brasil na área da segurança internacional e o papel das percepções da Argentina na definição da sua estratégia junto ao sócio do MERCOSUL; e sua hipótese é de que esses desentendimentos não foram resultantes de uma disputa de poder. Nessa linha, busca-se dialogar com a afirmativa recorrente na literatura de que os comportamentos da Argentina frente ao Brasil e aos EUA teriam tido vínculos, pesos e contrapesos no universo da política externa argentina (SPEKTOR, 2014; RUSSELL e TOKATLIAN, 2003).

Nosso ponto de partida teórico é a relação entre ideias e política externa em seu processo de formulação e implementação para melhor entender as escolhas dos tomadores de decisão da política externa argentina. Com o intuito de atribuir uma dimensão empírica à resposta, destacamos aqui dois episódios ilustrativos das principais divergências político-diplomáticas entre Brasil e Argentina de 1997 a 1999, e que têm os Estados Unidos como pano de fundo: i) a obtenção do status de aliado especial extra-OTAN por parte da Argentina, em 1997, com consequente reação negativa por parte do Brasil; ii) a oposição da Argentina ao pleito brasileiro por uma cadeira permanente no Conselho de Segurança das Nações Unidas, tema caro à diplomacia brasileira e que suscitou reações negativas por parte das autoridades argentinas.

Portanto, o artigo está focado no período de 1997 a 1999 e a área de concentração da diplomacia analisada é a dimensão político-diplomática ${ }^{2}$. Esta auxiliará na verificação de se há persistência de disputa de poder da Argentina com o Brasil, uma vez que envolve diretamente as autoridades políticas e diplomáticas presentes no policymaking de política externa. Para isso, foi desenvolvido um conceito central para explicar o ponto de vista da diplomacia argentina no período e a se contrapor à “disputa de poder”, própria do realismo: a “disputa por prestígio”.

O realismo explica que uma diferença de poder entre atores pode levar à necessidade de compensação de poder a partir do investimento interno no aumento das capacidades materiais ou a partir de alianças regionais ou extra-regionais (WALTZ, 1979). Com base nessa perspectiva, uma eventual disputa de poder poderia ter sido levada a cabo por parte da Argentina para contrabalançar o poder do Brasil a partir de uma aliança extra-regional com os Estados Unidos com base na política das relações carnais ${ }^{3}$ do governo Menem. No entanto, a conclusão da pesquisa infere a ausência dessa disputa de poder, mas a permanência de uma rivalidade mais branda, denominada aqui de "disputa por prestígio”. Esta última é aqui definida como um tipo de rivalidade subjetiva e simbólica, portanto, menos conflituosa, já que não evoca benefícios materiais. A inspiração do conceito se origina na "dimensão simbólica do poder nacional” e no "prestígio internacional” expressas na obra do Barão do Rio Branco ${ }^{4}$ e nas entrevistas conduzidas para a pesquisa, nas quais surgia repetidamente a palavra "prestígio" nas narrativas das autoridades.

\footnotetext{
${ }^{1}$ A resolução 911 foi uma medida protecionista do governo argentino, como resposta ao barateamento das exportações brasileiras após a brusca desvalorização do Real, permitindo a imposição de salvaguardas contra qualquer produto do MERCOSUL. A percepção de "ano mais difícil” é expressa pelo embaixador Herrera Vegas (LA NACIÓN, 2000).

${ }^{2}$ Sem desconsiderar a importância da área econômica, não será objeto deste artigo contemplar divergências ou disputas tais como a desvalorização da moeda brasileira em 1999 ou a adoção de medidas protecionistas, correspondentes ao âmbito comercial.

${ }^{3}$ A expressão "relações carnais" advém de um discurso de Di Tella, quando este defendeu carnalidad - no sentido de substância - na relação com os Estados Unidos. Após críticas da imprensa argentina, denominando a relação almejada de relaciones carnales, o próprio chanceler argentino passa a usar a expressão de relação carnal, em detrimento de uma relação platônica, em referência a busca de benefícios tangíveis a partir dessa relação com a superpotência (CISNEROS, 2004).

${ }^{4}$ Mello e Silva (1995) ressalta o que Rio Branco chamava de recursos materiais de poder e recursos simbólicos de poder.
} 
Dessa forma, para dar conta do objetivo, no campo metodológico, as fontes deste artigo se concentram em discursos de autoridades, matérias de imprensa da época e, principalmente, entrevistas com diplomatas brasileiros e argentinos. Essas entrevistas tomaram uma abordagem qualitativa e semiestruturada com objetivos exploratórios de pesquisa, possibilitando espaço de voz para a exposição dos entrevistados em torno do problema ${ }^{5}$.

\section{Argentina como aliada especial extra-OTAN: Aliada contra quem?}

O título desta seção tem por inspiração a indagação irônica de Fernando Henrique Cardoso (FHC), presidente brasileiro à época, ao tomar conhecimento do status recebido pela Argentina como aliada especial dos Estados Unidos extra-OTAN, em agosto de 1997: “aliados contra quem?” (apud SALOMON, 1997), pergunta criticando a aliança simbólica entre os dois países.

O flerte da Casa Rosada com a maior aliança militar do pós-Guerra Fria teve início nos primeiros anos da presidência de Carlos Menem, em 1992, com o discurso do chanceler Guido di Tella no Conselho de Representantes Permanentes do Atlântico Norte, em Bruxelas (LINS, 1999). O objetivo primário era negociar a entrada da Argentina na Organização do Tratado do Atlântico Norte como membro associado. A partir de então, os diplomatas argentinos começaram a trabalhar pela iniciativa (REFICCO, 1998). No entanto, somente no segundo mandato de Menem, a negociação da condição, não mais de aliado da OTAN, mas de aliado extra-OTAN dos Estados Unidos, é retomada na viagem de Menem ao país, em 1996, ocasião em que o presidente argentino formalizou a solicitação diante de Bill Clinton (CORTES, 2003, p.15).

Em sequência, o anúncio de que os EUA forneceriam o status à Argentina ocorreu extraoficialmente a partir da Secretária de Estado, Madeleine Albright, e, oficialmente, com a visita do presidente americano à Argentina, em outubro de 1997 (LA NACIÓN, 1997a). Nesta visita, segundo discursos de Clinton e sua delegação, os Estados Unidos reconheciam o esforço argentino ao identificar que a relação entre ambos passava por um momento excepcional, no qual destacava a aliança de valores entre os dois países (LA NACIÓN, 1997b). Ademais, ele reconhecia as participações militares da Argentina na segurança internacional, como o envio de navios militares para a Guerra do Golfo, de soldados para a ocupação militar do Haiti e para as forças de paz do Kosovo, além da missão da OTAN na Bósnia. No entanto, segundo Russell e Norden (2002, p.89), os EUA recompensaram a Argentina com o status de aliado extra-OTAN, mais por sua lealdade do que por seu papel no sistema internacional de segurança.

A notícia chegou ao Brasil em uma reunião entre diplomatas brasileiros e argentinos com a presenças dos chanceleres de ambos os países. O encontro, em agosto de 1997, visava à montagem de um mecanismo de consulta e coordenação bilateral em matéria de defesa e segurança internacional. $\mathrm{Na}$ ocasião, o chanceler argentino Guido di Tella recebeu um telefonema de Sandy Berger, então assessor de segurança nacional dos Estados Unidos, e comunicou em seguida aos diplomatas brasileiros do novo status recebido por Washington (BOTAFOGO GONÇALVES, 2017) ${ }^{6}$. Segundo o ex-embaixador do Brasil na Argentina, Botafogo Gonçalves, o ambiente transformou-se de um encontro amistoso e cordial em uma situação de desconforto entre as duas chancelarias.

\footnotetext{
${ }^{5} \mathrm{O}$ roteiro de perguntas compreendeu quatro kickoff questions: pergunta de pesquisa, hipótese de trabalho e cada um dos dois casos de divergência político-diplomática bilateral. As entrevistas foram conduzidas pessoalmente por Ariane Costa entre setembro de 2017 e março de 2018 , nas cidades do Rio de Janeiro e de Buenos Aires com os diplomatas brasileiros: Celso Amorim (Embaixador junto a ONU entre 1995 e 1999), Marcos de Azambuja (Embaixador na Argentina entre 1992 e 1997), José Botafogo (Embaixador na Argentina entre 2001 e 2003) e Luiz Felipe de Seixas Corrêa (Secretário Geral do Itamaraty entre 1999 e 2001); e com as autoridades argentinas: Andrés Cisneros (vice-chanceler entre 1992 e 1996), Fernando Petrella (Embaixador da junto a ONU entre 1996 e 1999), Juan Pablo Lohlé (Embaixador no Brasil de 2003 a 2011) e Carlos Escudé (assessor do Ministério das Relações Exteriores de 1991 a 1992). A seleção dos entrevistados se deu com o objetivo de equilíbrio de perspectivas entre tomadores de decisão brasileiros e argentinos, dotados de vínculo direto na relação entre os dois países ou participação ativa nos dois casos de disputa analisados. As autoridades argentinas Adalberto Giavarini (chanceler de 1999 a 2001), Diego Guelar (Embaixador no Brasil de 1996 a 1997) e Jorge Hugo Herrera Vegas (Embaixador no Brasil de 1997 a 2000) não responderam à solicitação de entrevista e Carlos Menem (presidente entre 1989 e 1999) negou a solicitação.

${ }^{6}$ Confirmado por Lampreia (2010).
} 
É imperativo destacar que o status de aliado especial tem relação com o alinhamento aos EUA e não com vínculo à OTAN. Segundo Madeleine Albright, esta é uma categoria que reconhece uma relação política especial com os EUA (SPEKTOR, 2014). Apesar da aliança representar um diálogo estreito com Washington, ela não implica em nenhum compromisso, em matéria de segurança por nenhuma das partes (Idem). À época eram também aliados especiais extra OTAN: Austrália, Coreia do Sul, Egito, Japão, Israel, Jordânia, e Nova Zelândia. Portanto, países cujas regiões implicavam questões de segurança mais prementes para os EUA do que a Argentina. Em resumo, o status de aliado extra-OTAN possui pouco valor substantivo, mas grande valor simbólico, uma vez que a Argentina era o oitavo país a receber esse status no mundo e o primeiro no continente americano. Na prática, porém, a posição lhe dava apenas acesso a equipamento militar excedente e participação em exercícios militares compartilhados (RUSSELL e NORDEN, 2002, p.88), pouco excedendo o plano da retórica (PICAZO, 2004, p.30).

Picazo (2004) destaca a possibilidade de um interesse estratégico subjacente dos EUA na aliança com a Argentina. Segundo o autor, tal aliança, representaria para o governo norte-americano uma compensação do poder ascendente do Brasil; isto é, um contrapeso na região sul-americana para os interesses estadunidenses. Em um contexto de pretensões de liderança regional do Brasil e de discursos do país como player global, o estreitamente de laços políticos dos EUA com a Argentina funcionaria como contrapeso, segundo essa perspectiva. Para Huntington (1999, p.47), o novo status fornecido à Argentina representaria a estratégia americana em melhorar as relações com a potência regional secundária da América do Sul, contrabalançando a emergência do Brasil $^{7}$, na qualidade de potência regional primária.

Desde o Brasil, esta perspectiva também se fazia sentir. O ex-presidente, então senador, José Sarney, importante participante do desenho da integração e cooperação Brasil-Argentina, atribuiu à administração Clinton a intenção de introduzir uma fratura no MERCOSUL: “Acredito que o povo brasileiro e o povo argentino [...] não permitirão que interesses menores [...] semeiem aquilo que os Estados Unidos desejam e que está muito claro: a desestruturação do MERCOSUL” (SARNEY, 1997). Adicionalmente, acusou a Argentina de ser instrumento de uma estratégia norte-americana para dividir os países do bloco (LA NACIÓN, 1997a) e apontou Menem como “instrumento de divisão do continente” (TORRES, 1997).

A reação negativa não veio somente do Brasil, mas também do Chile. O Presidente Eduardo Frei (1994-2000), criticou a atitude norte-americana alegando que traria desequilíbrio regional. Russell (1994) já afirmava que um dos custos do alinhamento argentino com os EUA era a geração de desconfianças e receios por parte dos países latino-americanos.

Por outro lado, as críticas do Presidente Cardoso não foram tão explícitas como as de Frei ou de Sarney. Ao contrário, as imprensas brasileira e argentina apontavam que o presidente brasileiro buscava minimizar o impacto prático do status (LA NACIÓN, 1997a). Em relato à Folha de São Paulo, FHC afirmou que não temia conspirações norte-americanas e acrescentou que "nós, brasileiros, não temos uma preocupação doentia com o que pensam os Estados Unidos" (SALOMON, 1997), em uma crítica clara ao modus operandi do governo Menem. Em termos político-diplomáticos, a indiferença transmitida pela presidência brasileira detinha muito mais representatividade nas relações exteriores do que um discurso inflamado do senador Sarney. Ao menos, as respostas a esse último nas imprensas argentina e norteamericana indicam que foi dessa forma que EUA e Argentina escolheram interpretar.

A primeira reação por parte dos EUA foi a de que as consequências foram inesperadas e de que a ideia de existência de um plano deliberado norte-americano para dividir a região fazia parte de uma "visão velha e estereotipada”. Na tentativa de reduzir o mal-estar na região, Washington declarou que o status era meramente simbólico e que Brasil e Chile poderiam ser nomeados como aliados extra-OTAN se assim almejassem. O porta-voz do Departamento de Estado, James Rubin, respondeu às acusações de Sarney afirmando que os EUA teriam boas relações com os dois países e que o status de "aliada militar íntima" dado à Argentina se devia ao reconhecimento de sua "boa cidadania mundial" (Idem). A partir do

\footnotetext{
${ }^{7}$ Uma análise das reais intenções de Washington para com a América do Sul no convite à Argentina para ser aliada especial extra-OTAN é tema para outra pesquisa.
} 
Secretário adjunto para Assuntos Interamericanos, Jeffrey Davidow, o governo dos Estados Unidos “desmentiu categoricamente que estivesse buscando fricções entre Argentina, Brasil e Chile” (LA NACIÓN, 1997a).

Contudo, em julho de 1999, por sugestão de seu Secretário de Planejamento Estratégico, Jorge Castro, a Argentina solicitou formalmente sua entrada à OTAN como membro associado ou de "categoria similar a se estabelecer" (SOLIANI; ROSSI, 1999). A solicitação ocorreu a partir de carta direcionada ao Presidente Clinton e ao Secretário-Geral da OTAN, Javier Solana, enviada por Menem, em seu último ano de governo (COLACRAI, 2004, p.19). Em resposta, o Itamaraty, por meio de comunicado oficial, criticou não ter sido consultado pelo governo argentino e acrescentou que um eventual aceite por parte da Organização “introduziria elementos estranhos ao contexto de segurança regional sul-americana” (Idem). A percepção brasileira era de que a Argentina buscava exercer unilateralmente a responsabilidade da segurança regional na qualidade de aliado especial dos EUA (CORTES, 2003, p.15). A incorporação da Argentina como aliado extra-OTAN confirmou a percepção do Brasil como um aliado econômico, e não como aliado estratégico. Tal separação já vinha sendo feita antes de 1997, mas a obtenção do status consolidou essa separação, na qual o alinhamento argentino com o Brasil se dava no campo econômico-comercial e o alinhamento com os EUA se dava no campo da defesa e da segurança.

Nesse período, em um gesto de rejeição simbólica, o Brasil desaconselhou a visita do Presidente Menem a Brasília em julho de 1999, a partir de uma coletiva de imprensa no Palácio do Planalto (CLARÍN, 1999). A justificativa era de efeito prático: o descontentamento brasileiro com a resolução 911 da Argentina, que afetava as exportações brasileiras para o país. No entanto, a leitura da imprensa era a de que o descontentamento original vinha do pedido de Menem de entrada na OTAN (Idem).

Como resultado lógico, os países da organização negaram a entrada da Argentina como membro associado. Ironicamente, a resposta negativa ao pleito chega às autoridades diplomáticas argentinas em telefonema recebido em Brasília diante de diplomatas brasileiros. Segundo Botafogo Gonçalves (2017), quando estavam presentes em uma das salas de reuniões do Itamaraty, um assessor de Guido di Tella o evoca para fora da sala para o telefonema. Ao retornar à sala, o chanceler argentino relata em primeira mão aos diplomatas brasileiros que o pedido argentino havia sido rechaçado, com a justificativa evidente de que a Argentina se encontra no Atlântico Sul, não atendendo ao requisito básico de pertencer a uma organização do Atlântico Norte. Formou-se, portanto, de um obstáculo geográfico um obstáculo jurídico, já que a organização não acolhia países de fora do seu hemisfério.

Para Celso Amorim, a questão do status de aliado dos Estados Unidos extra-OTAN não tinha importância para o Itamaraty, mas se a Argentina entrasse na organização como membro "seria um problema” (AMORIM, 2018). Para o Chefe da Divisão de Assuntos internacionais da ESG, Manuel Cambeses Júnior (1999), foi surpreendente que a Argentina tenha proposto o seu ingresso na maior aliança militar do mundo sem efetuar consultas diplomáticas prévias aos países sócios do MERCOSUL.

Diferentemente dos demais países com igual status à época, a Argentina não necessitava da proteção do guarda chuva americano de defesa (REFICCO, 1998). O objetivo da Casa Rosada de entrada na OTAN não se deu por uma questão de ampliação da margem de segurança do país com base na percepção de ameaças, uma vez que a gestão Menem já não pensava mais em termos militares. Ao contrário, o objetivo se concentrava na inserção do país no Ocidente, integrando-se a partir de uma de suas instituições mais representativas (idem). Também para Picazo (2004, p.80), a aliança representava mais uma peça na política de alinhamento.

Desde o início de sua gestão, o chanceler Guido Di Tella demonstra em seus discursos a importância da Argentina ser reconhecida como pertencente ao "Clube do Ocidente". Objetivo este baseado na demonstração oficial do reconhecimento dos EUA de que a Argentina não era mais a "ovelha negra” do passado, mas que havia se tornado um país de confiança no sistema internacional: "Nós queremos pertencer ao Clube do Ocidente. Eu quero ter uma relação cordial 
com os Estados Unidos e não queremos um amor platônico. Nós queremos um amor carnal com os EUA. Nos interessa, porque podemos tirar um benefício"8 (Di Tella, apud Reficco, 1998, p.80) ${ }^{9}$.

O fragmento acima, datado do primeiro ano da gestão do chanceler, foi o responsável original pela caracterização pública das “relações carnais”, figurando o esforço de Guido di Tella de tornar pública a nova orientação de política externa da sua gestão. O desejo de pertencimento ao "Clube do Ocidente" levou a uma série de ações da Argentina de acercamento aos EUA e ao Atlântico Norte, fazendo parte desta lógica o próprio pleito de entrada como membro associado à OTAN. Este último é comparável ao interesse em entrar na Organização para Cooperação e Desenvolvimento Econômico (OCDE). O objetivo em ambos os casos é mais simbólico do que prático, na busca de um atestado perante o sistema internacional de sua identidade como democracia, economia de mercado e de defesa dos direitos humanos. De fato, as declarações públicas do governo norte-americano destacaram a qualidade de "ator de confiança” nas justificativas para o fornecimento do status, o que demonstra que o esforço foi bem-sucedido dentro dos objetivos traçados pelo governo Menem.

Assim, o empenho argentino de entrada na OTAN é explicado pela busca de aproximação e aceitação do Ocidente e não de contrabalançar o poder do Brasil. Na própria visão do Itamaraty, o novo status argentino de aliado dos EUA extraOTAN não era percebido como ameaça ou rivalidade. Ao contrário, era encarado com comicidade por parte dos diplomatas à época. Para o embaixador Botafogo Gonçalves, o episódio foi percebido de maneira jocosa pelo Itamaraty, o que foi confirmado também pelo Ministro Celso Amorim (2018). Para Azambuja (2018), “a Argentina já havia convencido aos EUA de suas intenções, não havia a necessidade de cambalhotas políticas.”

\section{Brasil e o pleito pela cadeira permanente no CSNU: candidato natural para quem?}

Segundo Russell e Tokatlian (2011), as divergências entre Brasil e Argentina alcançaram seu ponto alto na questão da reforma do Conselho de Segurança das Nações Unidas. Desde a extinta Liga das Nações o Brasil aspira a um assento permanente na instância decisória do concerto de países. Com o fim da Guerra Fria, a necessidade de reforma do Conselho tornou-se ainda mais latente. Em 1989, o presidente brasileiro José Sarney propôs o alargamento do CSNU sob a defesa do aumento da representação dos países periféricos, em discurso na Assembleia Geral (SARNEY, 1989, p.625-626). Cinco anos depois, o Brasil apresentou formalmente a sua candidatura para a ocupação de um assento permanente na ocasião de abertura da AGNU de 1994.

Ao longo da década de 1990, a aspiração do Brasil sobre a cadeira permanente apresentou fôlego maior no governo de Itamar Franco (1993-1994) e no primeiro mandato de Cardoso (1994-1998), quando o país contava com a presença de Celso Amorim como chanceler e embaixador do Brasil junto às Nações Unidas, respectivamente. Amorim era conhecido como um diplomata que alimentava grande apelo pela busca do assento permanente no CSNU. Segundo Lampreia (2010), essa era uma “obsessão de Amorim de maneira muito estridente”. E se o próprio chanceler brasileiro do período enxergava dessa maneira, não poderia ser outra a percepção dos diplomatas argentinos

Ainda no decorrer dos anos 1990, a Argentina demonstrou forte interesse na participação em assuntos de segurança internacional, chegando a garantir uma cadeira rotativa no CSNU nos biênios de 1994-1995 e 1999-2000 (CORIGLIANO, 2003a, p.232). A divergência com o Brasil em torno da questão do Conselho de Segurança era um tema caro à Argentina. Prova disso é o fato de o tema ter sido alvo de diálogo entre o chanceler Guido di Tella e a Secretária de Estado Madeleine Albright, no qual o chanceler expunha diretamente a oposição argentina por um assento permanente para o Brasil (SPEKTOR, 2014).

\footnotetext{
${ }^{8}$ Nosotros queremos pertenecer al Club de Occidente. Yo quiero tener una relación cordial con los Estados Unidos y no queremos un amor platónico. Nosotros queremos un amor carnal con Estados Unidos. Nos interesa, porque podemos sacar un beneficio.

${ }^{9}$ A fonte original foi artigo de Di Tella, publicado no jornal Página 12, em 1999.
} 
A posição da Casa Rosada se manteve historicamente desde a Liga das Nações na oposição da existência de membros mais privilegiados que outros em fóruns multilaterais. Sem mudanças de posição ao longo dos diferentes governos, a Argentina manifestou oposição direta à proposta brasileira de reforma do Conselho, opondo-se sistematicamente a apoiar suas aspirações (RUSSELL, 2010, p.279). Para evitar maiores divergências com o Brasil, o país formulou a alternativa aos moldes onusianos de criação de cadeiras rotativas para dois ou três países da América Latina com mandatos temporários. Segundo essa perspectiva, a reforma deveria se dar a partir da incorporação de novos membros, mas sem um caráter permanente (idem, p.233). No entanto, a sugestão alternativa não parecia vantajosa para o Itamaraty. Para Celso Amorim, as vagas rotativas por região já existiam sem a necessidade de reforma (AMORIM, 2018).

Como autoridade que lidou de frente com a oposição argentina, Amorim relata que sentiu "rivalidade forte" no tema da reforma do CSNU em Nova Iorque. Exemplo disso, é o episódio relatado por ele na ocasião de uma visita de cordialidade à sua contraparte argentina quando assume o posto de embaixador junto às Nações Unidas. É de praxe que o novo indicado para a posição do Brasil realize uma visita ao representante argentino, e vice-versa, na qualidade de primeiro gesto político quando alocado no posto. Nesse contexto, Amorim lembra que, em sua primeira visita ao embaixador argentino, à época, o embaixador Emilio Cárdenas, surpreendeu-se com o conteúdo objetivo e seco do primeiro recado do diplomata: "sou contra a entrada do Brasil no Conselho de Segurança". Segundo Amorim, um tema que nem ao menos estava na pauta da reunião.

No discurso de Amorim na Assembleia Geral em 1994, a representação da região e dos países em desenvolvimento era mencionada pelo Brasil como uma das justificativas de legitimidade para a sua candidatura: "a região da América Latina e do Caribe deve estar contemplada em qualquer ampliação do Conselho” (AMORIM, 1994). Ainda no mesmo discurso, ao afirmar "somos parte da América Latina e orgulhamo-nos de estarmos inseridos em sua longa história de paz", o ex-chanceler destacava também as credenciais pacíficas da região, posicionando o Brasil indiretamente como representante regional. Quando questionado sobre a posição argentina de não se sentir representada pelo Brasil, Amorim explica "o Brasil se coloca como representante como força de expressão. Na prática, os países não representam as suas regiões dentro do Conselho" (AMORIM, 2018).

Em 1995, Strobe Talbott, Secretário de Estado adjunto, ponderou que os Estados Unidos referendariam o pleito brasileiro se o Brasil obtivesse o apoio da comunidade latino-americana (ARRAES, 2005, p.9). No entanto, a Argentina seguia firme em defesa da rotatividade da cadeira no continente, o que demonstrava a falta de consenso entre os dois vizinhos e, adicionalmente, do México, que também seguia sua tradição de oposição a um eventual assento permanente para o Brasil .

No ano seguinte, ocorreu um esvaziamento do tema, tanto na ONU quanto no Brasil, que, por sua vez, diminuiu o perfil dado à região na candidatura devido à oposição argentina (ARRAES, 2005). Lampreia, inclusive, realiza um discurso na AGNU em 1996, no qual afirma que o assento permanente não era uma prioridade brasileira (LAMPREIA, 1997b). O próprio Lampreia não era tão enfático em relação à questão do assento permanente, ponderando as responsabilidades adicionais que a posição traria para o Brasil, inclusive, em termos financeiros:

[...] é necessário um debate amplo sobre as responsabilidades concretas que nos incumbiriam como membro permanente, já que, além do ônus financeiro [...] essa condição implica não a obrigatoriedade, mas a disposição de participar mais ativamente em operações de paz e o imperativo de termos preparo e disponibilidade militar para fazê-lo de forma ágil (LAMPREIA, 1997b).

Em depoimento oral, Lampreia (2010) ainda explica que desde antes da posse de Cardoso em 1995, o presidente e ele concordaram que o tema do CSNU "não devia ser uma obsessão brasileira” e que o MERCOSUL, assim como o relacionamento com os vizinhos e com os EUA eram a prioridade do governo em matéria de política externa. Dessa forma, ao mesmo tempo que reduzia o perfil da candidatura do Brasil, Lampreia solicitava à sua contraparte na Argentina menos alarde na oposição sobre o tema: 
Em 1996, porque já tínhamos tido a convicção de que o assunto não iria andar, foi a afirmação que eu fiz ao Guido di Tella de que nós não renunciaríamos a nossas ideias, mas que não transformaríamos isso em uma prioridade muito vocal, muito acentuada da nossa posição e manteríamos um perfil baixo no assunto sempre que a Argentina não procurasse fazer uma campanha antibrasileira também nesse campo. (LAMPREIA, 2010, p.200)

Adicionalmente, o chanceler brasileiro relata que as desavenças entre ambos os países sobre a reforma do CSNU carregavam o efeito de se espalhar para outras áreas e temas, prejudicando eventualmente a relação bilateral como um todo: "O assunto ameaçava repercutir sobre tudo, não é? Porque mesmo que fosse uma brasa dormida, essa questão da rivalidade Brasil-Argentina podia de repente ser insuflada aí por um episódio como esse e virar um caso e um entrave ao progresso em todas as áreas" (LAMPREIA, 2010, p.200).

No entanto, a trégua termina em 1997, quando a ONU e o Itamaraty retomam as discussões sobre a reforma. Menem realiza uma declaração pública criticando a posição brasileira e defendendo que a presença do vizinho como membro permanente do Conselho traria "graves desequilíbrios regionais” (GRONDONA, 1997). Rebatendo a colocação de Menem, Lampreia escreve artigo na Folha de São Paulo mencionando surpresa e desagrado com a posição do presidente argentino:

A reforma do conselho não é um tema central, estrutural, nas relações entre o Brasil e a Argentina ou para o Mercosul. Nosso interesse principal na questão foi resguardado: não queremos que o assunto afete adversamente as relações com a Argentina nem a coesão do Mercosul. Não queremos que se instrumentalizem esse e outros temas para criar a cizânia entre parceiros especiais, nem para introduzir falsos elementos de barganha que jamais aceitaríamos (LAMPREIA, 1997a).

O artigo de agosto de 1997 é escrito poucas semanas após o incômodo episódio da reunião de Itaipava. Diante do breve estremecimento das relações entre as duas diplomacias devido ao novo status de aliado extra-OTAN da Argentina, o Brasil levanta o tom do discurso no tema do CSNU. No mês seguinte, em discurso na AGNU, Lampreia rechaça a proposta argentina de rodízio e relança o tema da candidatura do Brasil, afirmando que o país seria um candidato natural para uma eventual cadeira. A reação incisiva de Lampreia (1997b) tira da margem de discussão da Argentina a questão da reforma do CSNU, alegando não ser tema de interesse bilateral ou regional. Na ocasião da reunião de Itaipava, Lampreia explica que "Guido" e ele conversaram muito sobre as posições em relação à reforma do CSNU e estava claro que havia uma forte cisão entre os dois países (LAMPREIA, 2010).

Em Buenos Aires, a repercussão do pleito brasileiro pela cadeira permanente foi muito negativa, segundo Marcos de Azambuja (2018), embaixador em Buenos Aires no período. De fato, a Argentina foi a responsável pela oposição mais forte a uma vaga permanente para o Brasil. Segundo as palavras de Lampreia (2010), “o pior problema era a Argentina, especialmente, a chancelaria e, sobretudo, Petrella que detinha uma posição muito forte a esse respeito”. Fernando Petrella era diplomata de carreira e havia sido indicado para a posição de Representante da Missão Permanente da Argentina junto à ONU entre 1996 e 1999, um dos postos mais importantes da diplomacia argentina, junto com as embaixadas em Washington e em Brasília.

Em 1999, a oposição sustentada por Petrella teve influência direta na confecção do discurso de Menem na AGNU daquele ano. No discurso, o presidente argentino se opõe taxativamente à reforma do CSNU no formato que o Brasil defendia, reiterando a posição argentina de que a categoria de membro permanente "não se deve introduzir nas regiões nas quais [a categoria] não existe" ${ }^{10}$ (LA NACIÓN, 1999). Em entrevista com jornalistas, quando questionados sobre o tom da afirmativa, Guido di Tella comenta que o texto definitivo do discurso teve modificações de última hora redigidas por ele próprio e por Fernando Petrella (Idem). A atuação deste último era caracterizada por Lampreia como aquele que adota posturas excessivamente antibrasileiras (LAMPREIA, 2010). Opinião essa compartilhada por outros diplomatas brasileiros

\footnotetext{
${ }^{10}$ no debe introduzirse en las regiones en las que [la categoria] no existe.
} 
e argentinos, sendo confirmada a partir de depoimentos orais do embaixador brasileiro Botafogo Gonçalves (2017) e do embaixador argentino Pablo Lohlé (2017), segundo os quais Petrella tinha reservas em relação ao Brasil.

A questão, portanto, não reside na ausência de apoio oficial da Argentina per se, mas na justificativa para tal defendida pelo governo Menem: desequilíbrio de poder regional. O discurso da presidência se baseava em questões de política de poder e alteração do equilíbrio regional - o que revela inconsistência com as narrativas dos diplomatas argentinos, dentre eles, o próprio Petrella que sustentava ausência de rivalidades com o Brasil. Quando indagado sobre a existência de algum vestígio de rivalidade na oposição argentina ao pleito brasileiro, Petrella responde que "a oposição argentina é ao sistema atual do CSNU e não ao Brasil, não havendo motivos para a Argentina alimentar qualquer rivalidade regional com seu vizinho (PETRELLA, 2017). Adicionalmente, Petrella compara o Brasil aos demais membros do G-4 ${ }^{11}$, explicando que a oposição recebida por Índia, Japão e Alemanha, sustentada por Paquistão, China e França, respectivamente, em relação aos interesses de uma cadeira permanente correspondem a rivalidades geopolíticas regionais históricas que não existem entre Brasil e Argentina. O diplomata adiciona ainda que "o Brasil construiu um complexo de culpa na Argentina por não termos apoiado o seu pleito” (PETRELLA, 2017).

Apesar da oposição assertiva de Petrella, a reação dos argentinos à reforma do CSNU aos moldes brasileiros não era consensual. Havia críticas por parte de uma oposição na Argentina que defendia a priorização da parceria com o Brasil. Escudé (1998), na contramão da versão oficial da diplomacia argentina, defendia que o país apoiasse o pleito brasileiro. Em uma perspectiva pragmática, explica que, uma vez que a Argentina não tem a influência necessária para adquirir um assento próprio para si, faria sentido apoiar o vizinho na empreitada. "É imperativo que a Argentina apoie o Brasil nesta e outras questões similares. [...] Argentina não pode competir por esse assento no Conselho. Se não apoia o Brasil em relação a temas nos quais os EUA estão dispostos a apoiá-lo, de que vale ao Brasil a aliança com a Argentina?"12 (ESCUDE, 1998, p.76).

Em depoimento oral, Escudé confessa que as chances de o Brasil lograr o assento eram tão ínfimas que a Argentina teria muito mais a ganhar se o apoiasse em detrimento de uma oposição ao pleito brasileiro (ESCUDÉ, 2017).

Entre a assertiva oposição de Petrella e o apoio pragmático de Escudé, ainda havia aqueles que apoiavam o assento permanente para o Brasil, mas não da forma como estava sendo buscada pelo Itamaraty. Nesse meio-termo se posicionavam figuras como o vice-chanceler Andrés Cisneros e o jornalista argentino Mariano Grondona. Para Cisneros, as diferenças existentes entre Brasil e Argentina eram mais aparentes que profundas (CISNEROS, 2018). Segundo ele, a divergência não estaria na proposta final, mas na via escolhida pelo Brasil para se chegar a ela. Na perspectiva de Cisneros, havia duas vias para se reivindicar uma posição de membro permanente: a "via oligárquica”, com base no peso econômico, político e militar, e a "via democrática”, com base no poder de representatividade da região em que está inserido. Isto exposto, Cisneros defende que o Brasil se candidatasse não pelo seu peso individual, mas por seu peso de representatividade. Para ele, os assentos adicionados com a reforma não deveriam ser permanentes, mas temporários, sendo ratificados pela própria região de tempos em tempos. Em síntese, Cisneros finaliza:

Se pretende ir porque representa a região, é a região que debe enviá-lo, e não solicitar a entrada por porta democrática, mas apresentando argumentos da porta oligárquica: 'eu tenho um grande PIB, muita população e território para que o escolham as grandes potências e não os vizinhos da região' [...] corresponde demarcar que se trata de um exemplo das relações que o Brasil deve manter com seus vizinhos: se hegemon ou líder. ${ }^{13}$

\footnotetext{
${ }^{11}$ Fórum de quatro países que se apoiam no pleito por uma cadeira permanente no CSNU.

${ }^{12}$ Resulta imperativo que Argentina apoye a Brasil en esta y otras cuestiones similares. [...] Argentina no puede competir por ese asiento en el Consejo. Si no apoya a Brasil respecto de temas en los que Estados Unidos están dispuestos a apoyarlo, ¿de qué le vale a Brasil la alianza con Argentina?

${ }^{13}$ si pretende ir porque representa a la región, es la región la que debe enviarlo, y no reclamar la entrada por la puerta democrática, pero esgrimiendo argumentos de la puerta oligárquica: 'yo tengo mucho PBI, población y territorio para que lo elijan a dedo las grandes potencias y no sus vecinos de la región' [...] corresponde puntualizar que se trata de un ejemplo de las relaciones que Brasil quiere mantener con sus vecinos: si como hegemón o como líder. Idem.
} 
Na mesma linha de raciocínio, Mariano Grondona defende em coluna no La Nación em 1997, o apoio de seu país a uma cadeira permanente do Brasil como um gesto de elegância, maturidade e reconhecimento (GRONDONA, 1997). Contudo, ele também critica a forma unilateral com a qual o Brasil defendia a reforma, afirmando que o Brasil não deve candidatar-se a porta-voz da América Latina sem ter dialogado antes com a mesma: "Ou atua em um mundo como portavoz de uma região a qual se sente intimamente ligado ou se situa um isolamento dourado com sua pretensão de grandeza como única companhia”. Para Grondona, “ou o Brasil é a cabeça do leão ou o leão” ${ }^{14}$. Isto é, ou se identifica como portavoz de uma região ascendente ou como potência emergente que avança sozinha como ator global.

Colocar-se mesmo que indiretamente, como representante de uma região que não lhe outorgou esse status de representante é, de fato, problemático. Por mais que o apelo regional não tenha sido insistido ao longo dos anos após o discurso de Amorim em 1994 na AGNU, a Argentina demonstrou que, na qualidade de país vizinho, sócio originário do MERCOSUL e, ainda, aliado estratégico, gostaria de ser consultada pelo Brasil em movimentos globais como esse.

Para Seixas Corrêa e Amorim, seria natural que houvesse desconforto dos vizinhos em relação às ações brasileiras devido ao tamanho do Brasil (SEIXAS CORRÊA, 2018; AMORIM, 2018). Para outros, teria havido baixa sensibilidade dos diplomatas brasileiros com a Argentina no caso da reforma do CSNU. Para Botafogo Gonçalves, um dos embaixadores brasileiros mais reconhecidos pela defesa da integração e cooperação entre Brasil e Argentina, o Brasil tomou uma postura arrogante em relação ao vizinho ao não dialogar sobre o seu pleito por um assento permanente na ONU (BOTAFOGO GONÇALVES, 2017).

No quadro abaixo estão representadas as três posições de autoridades argentinas no tema de uma cadeira permanente para o Brasil no Conselho de Segurança:

\begin{tabular}{|c|c|c|}
\hline Oposição total & Apoio parcial & Apoio total \\
\hline $\begin{array}{c}\text { Fernando Petrella } \\
\text { (diplomata de carreira) }\end{array}$ & $\begin{array}{l}\text { Andrés Cisneros (cientista } \\
\text { político, vice-chanceler) }\end{array}$ & $\begin{array}{l}\text { Carlos Escudé (acadêmico, } \\
\text { assessor da chancelaria) }\end{array}$ \\
\hline $\begin{array}{c}\text { “Brasil sócio”: enxerga o Brasil } \\
\text { horizontalmente, sem divisões } \\
\text { de Norte-Sul no entorno } \\
\text { regional }\end{array}$ & $\begin{array}{c}\text { “Brasil líder”: reconhece o peso } \\
\text { diferente entre os países e } \\
\text { enxerga o Brasil como ator } \\
\text { relativamente mais poderoso }\end{array}$ & $\begin{array}{c}\text { “Brasil aliado”: não só } \\
\text { reconhece, mas alerta para o } \\
\text { peso diferente entre os países, } \\
\text { enxergando o Brasil como } \\
\text { superior, em termos de poder. }\end{array}$ \\
\hline $\begin{array}{l}\text { Oposição total à cadeira } \\
\text { permanente do Brasil e ao } \\
\text { sistema do CSNU }\end{array}$ & $\begin{array}{l}\text { Apoio ao assento permanente } \\
\text { para o Brasil, mas pela via } \\
\text { democrática e não pela via } \\
\text { oligárquica }\end{array}$ & $\begin{array}{c}\text { Apoio ao assento permanente } \\
\text { para o Brasil, independente da } \\
\text { via. }\end{array}$ \\
\hline $\begin{array}{l}\text { Justificativa: o CSNU deve ser } \\
\text { mais democrático, ao invés de } \\
\text { incluir mais atores ao seu "clube } \\
\text { de elite”. }\end{array}$ & $\begin{array}{l}\text { Justificativa: o Brasil deve } \\
\text { candidatar-se com o aval dos } \\
\text { países da região, garantindo } \\
\text { interlocução e } \\
\text { representatividade aos seus } \\
\text { vizinhos }\end{array}$ & $\begin{array}{l}\text { Justificativa: pragmatismo e } \\
\text { apoio ao vizinho em troca de } \\
\text { benefícios materiais. }\end{array}$ \\
\hline
\end{tabular}

Desde a visão do realismo periférico, que pautou em grande parte a política externa do governo de Menem, as relações econômico-comerciais deveriam ser priorizadas e, neste caso, a posição de rejeição do pleito brasileiro pelo governo argentino seria de cunho geopolítico ${ }^{15}$. O princípio básico do paradigma não condiz com a lógica da disputa por

\footnotetext{
${ }^{14} \mathrm{U}$ opera en un mundo como vocero de una región a que se siente intimamente ligado o se ubica en un dorado aislamiento con su pretensión de grandeza como única compañía. / o Brasil es la cabeza del leon o el leon.

${ }^{15}$ O governo de Menem assumiu suas ideias do realismo periférico, de Carlos Escudé (1992) em quase sua totalidade, com exceções pontuais como o não apoio ao Brasil a uma cadeira permanente no CSNU.
} 
prestígio: não faz sentido, para essa teoria, que a Argentina dispense energia rivalizando com um ator mais forte, mas aliar se a ele para tirar benefícios dessa relação.

No entanto, há que se levar em conta a ausência de consulta do governo brasileiro ao seu parceiro estratégico; postura que, nas esferas diplomáticas, resulta em mal-estar. Sendo assim, qual é a base ideacional da oposição argentina ao Brasil?

Algumas questões simbólicas nacionalistas de prestígio perpassam diversos governos de diferentes orientações na Argentina. A questão da reforma do CSNU passou por uma questão de prestígio, seja por não autorizar o vizinho a adquirir uma posição hierarquicamente mais alta no concerto de nações ou por não autorizar a candidatura desse mesmo vizinho sem o aval explícito argentino para a ocupação dessa posição.

Há uma diferença central entre as definições dos conceitos de rivalidade e disputa por prestígio. De um lado, a rivalidade pressupõe a concorrência entre pares que competem entre si em torno de um mesmo objetivo. No entanto, não é esse o caso das principais divergências político-diplomáticas entre Brasil e Argentina no período. A Argentina não almejava um assento permanente no CSNU, tampouco o Brasil, à época, pretendia qualquer tipo de associação à OTAN, seja como membro associado ou aliado especial dos EUA. Por outro lado, a disputa por prestígio por parte da Argentina pressupõe uma busca por notoriedade e reputação entre os pares, sendo essencialmente simbólica, uma vez que a demanda é por valores e não objetivos de razão prática. Tanto o assento permanente almejado pelo Brasil quanto a entrada na OTAN almejada pela Argentina faziam parte de símbolos de notoriedade e reputação no cenário internacional. Em suas definições, a rivalidade é essencialmente pragmática, enquanto a disputa por prestígio é essencialmente subjetiva e simbólica e, portanto, usualmente, menos frontal, já que não evoca benefícios materiais.

A disputa é então de prestígio e não de poder; fica claro como as posições mais assertivas se concentram na diplomacia argentina e não em outras posições burocráticas do governo. Exemplo disso é um dos relatos da experiência mencionada no depoimento de Celso Amorim: quando embaixador junto à ONU, conheceu uma autoridade argentina que não era diplomata de carreira e à época em que se conheceram, não via problema no apoio ao Brasil na questão do assento permanente. No entanto, após indicado ao posto diplomático, essa mesma autoridade passou a defender categoricamente o não apoio (AMORIM, 2018). Apesar de não ter relatado o nome da autoridade, a pesquisa indica que se tratava do Andrés Cisneros, que em entrevista afirmou apoio ao Brasil a um assento no Conselho e também em discurso no Itamaraty. No entanto, em 1999, quando ainda era Secretário de Relações Exteriores e Assuntos Latino-americanos do MREC, opôs-se de maneira assertiva ao pleito brasileiro por um assento permanente, alegando a justificativa oficial de desequilíbrio regional:

[...] A notória harmonia das Relações entre os países do Cone Sul da América garantiria que a rotação resultaria de aplicação simples. [...] Neste sentido, não pretendemos nem propor uma candidatura excludente da Argentina nem aceitar uma candidatura excludente de nenhum outro membro da região (CISNEROS, apud CORIGLIANO, 2003b, p.237). ${ }^{16}$

Somado a isso, Domingo Cavallo, o segundo homem mais importante do governo Menem, somente após deixar o Ministério da Economia e, portanto, se libertar das posições oficiais do governo, relatou à imprensa que apoiava um assento permanente para o Brasil (TORRES, 1997). A sua postura confirma que a disputa não era de razões práticas, senão simbólicas. Isto é, nada indica a existência de uma real preocupação de que o Brasil ocupe a posição, mas, simultaneamente, seria vedada a possibilidade de apoio quando em uma posição em cargo público.

\section{Considerações finais: prestígio ou poder?}

\footnotetext{
${ }^{16}$ La notoria armonía de las relaciones entre los países del cono sur de América garatizaría que la rotación resultaría de muy sencilla aplicación [...] En tal sentido no pretendemos ni proponer una candidatura excluyente de la Argentina ni aceptar una candidatura excluyente de ningún otro miembro de la región. Fonte do capítulo: Memorandum del vicecanciller Andrés Cisneros al canciller Guido di Tella sobre Consejo de Seguridad, sin fecha, en Archivo personal de Andrés Cisneros, Caja n7, Carpeta Consejo de Seguridad.
} 
As divergências político-diplomáticas elencadas neste artigo demonstram uma disputa por prestígio, não de poder, na relação da Argentina com o Brasil: a Argentina não aspirava a uma cadeira permanente no CSNU, assim como o Brasil não aspirava à entrada na OTAN. Em comum, no entanto, os dois pleitos representaram comportamentos unilaterais em relação ao vizinho. A ausência de diálogo foi marcada em ambas as situações, trazendo esfriamento pontual e incômodo entre as respectivas chancelarias.

Dentro das regras diplomáticas, iniciativas desse porte, sem consultar o aliado estratégico, parceiro comercial e fundador do MERCOSUL, representaria uma atitude condenatória. O realismo periférico diagnostica uma diferença ampla de poder entre Argentina e Brasil e, como resultado, prescreve a aliança em detrimento do balancing: aliança com os EUA no nível mundial e com o Brasil no nível regional; não preconizando uma disputa por poder, tampouco prescrevendo uma relação triangular pendular, mas complementar.

Cabe destacar que as relações entre Brasil e Argentina não foram relações entre equivalentes, por mais que o discurso oficial assim os tratasse (RUSSELL, 2010, p.279). Com base nas entrevistas, é possível afirmar que havia no MREC da Argentina um ethos institucional que padroniza o comportamento sobre questões como a oposição a uma cadeira permanente para o Brasil no CSNU. Desse modo, diferentes gerações da chancelaria argentina parecem herdar uma disputa por prestígio em relação ao Brasil. Não se competem capacidades materiais ou posicionamentos sistêmicos, já que a diferença entre os atores não mais permite esse tipo de rivalidade, mas ainda há espaço para uma disputa baseada em status, seja ele o de aliado especial dos Estados Unidos, membro associado da OTAN ou de membro permanente no Conselho de Segurança. Nessa linha, a chancelaria argentina, com suas características de um estamento burocrático soberanista, ganha centralidade, uma vez que seu ethos institucional privilegia posições nacionalistas.

É necessário, no entanto, destacar a diferença daqueles que são diplomatas de carreira e, portanto, passaram pela formação de um pensamento coletivo, internalizando determinadas diretrizes dos que são indicados para cargos diplomáticos temporários ou autoridades políticas. Estes últimos seguem as linhas da instituição, mas não necessariamente concordando com elas - caso do vice-chanceler Cisneros e do ministro da economia Cavallo na questão da reforma do CSNU. Existia ainda no interior da chancelaria argentina, sobretudo dentre os diplomatas mais antigos conhecidos como "geração Bacia do Prata", uma tendência a alimentar maior disputa com o Brasil, a partir da memória histórica das rivalidades bilaterais na bacia platina, na década de $1960^{17}$.

Como resultado, os dados analisados indicam a presença de disputa, não de poder material, geopolítico ou militar, mas de prestígio com o Brasil, especialmente, por parte da chancelaria argentina e, ainda em maior grau, nas gerações mais antigas. Tornou-se evidente que razões dessa natureza ainda guardam importância na década de 1990 e são usualmente confundidas com uma rivalidade mais frontal. As disputas simbólicas por prestígio foram fortes o suficiente para influenciar o desenho da política externa argentina com o país vizinho. Por isso, o alinhamento da Argentina com os Estados Unidos não poder ser explicado como causa preponderante das disputas de poder para rivalizar ou contrabalançar o Brasil.

De todo modo, é consensual que o lugar do Brasil na política externa argentina possui centralidade. A embaixada argentina em Brasília é das mais importantes juntamente com Washington e Nova Iorque. A relação com o Brasil não se traduz apenas no nível de comércio, de dados macroeconômicos e de inserção internacional do país, mas também em influência política, cultural, negociações conjuntas de política internacional e na integração regional.

No entanto, embora já tenha havido no passado momentos de disputa de poder e acirramento da rivalidade, ficou demonstrado que, nessas duas circunstâncias que marcaram desencontros entre ambos os países no campo da política externa, e desde o viés da diplomacia, houve uma disputa por prestígio. Por fim fica um incentivo para pesquisas futuras

\footnotetext{
${ }^{17}$ Foi incluída aqui a década de 1980, por esta ser destacada como o melhor período das relações bilaterais Brasil-Argentina (SARAIVA, 2012) e por ser o período de assinatura de diversos acordos que levaram culminaram no MERCOSUL.
} 
sobre se à medida que as gerações diplomáticas argentinas se renovam essa disputa por prestígio na relação com o Brasil se ameniza ou se potencializa.

\section{Referências}

AMORIM, Celso Discurso do Ministro Celso Amorim na AGNU 1994. In: SEIXAS CORREA, Luis F. (org), O Brasil nas Nações Unidas 1946-2006. Cap.1994, p.579-589. Brasília: FUNAG, 2007.

AMORIM, Celso. Entrevista, Rio de Janeiro, 17/03/2018.

ARBILLA, José M. Arranjos Institucionais e Mudança Conceitual nas Políticas Externas Argentina e Brasileira (1989-1994). Contexto Internacional, Rio de Janeiro, v.22, n.2, p.337-385, 2000.

ARRAES, Virgílio C. O Brasil e o Conselho de Segurança da Organização das Nações Unidas: dos anos 90 a 2002 . Revista Brasileira de Política Internacional, v.48, n.2, p. 152-168, 2005.

AZAMBUJA, Marcos de. Entrevista. Rio de Janeiro, 13/03/2018.

BOTAFOGO GONÇALVES, José. Entrevista. Rio de Janeiro, 13/09/2017.

CAMBESES JUNIOR, Manuel. A inserção da Argentina na Otan. Monitor Mercantil, São Paulo, 13/08/1999. Disponível em: <https://monitormercantil.com.br/a-inseruuo-da-argentina-na-otan>. Acesso em: 30 abr. 2020.

CLARÍN. Pelea en el Mercosur, gestos políticos sin precedentes, Clarín, Buenos Aires, 29/07/1999. Disponível em: <https://www.clarin.com/economia/brasil-insiste-desaconsejar-visita-carlosmenem_0_S1QFb6e0tl.html>. Acesso em:23 abr. 2020.

CISNEROS, Andrés. Entrevista, Buenos Aires, 09/01/2018.

COLACRAI, Miryan. La Política Exterior hacia los Vecinos durante los '90. Centro de Estudios Internacionales y de Educación para la Globalización (CEIEG). Documento de Trabajo No 1. 07/2004.

CORIGLIANO, Francisco. La dimensión bilateral de las relaciones entre Argentina y Estados Unidos durante la década de 1990: el ingreso al paradigma de 'relaciones especiales'. In: C. Escudé (ed.) Historia General de las Relaciones Exteriores de la República Argentina - Tomo XV - Las 'Relaciones Carnales', los vínculos políticos con las grandes potencias 1989-2000. Cap.1, p.15-205. Buenos Aires: Nuevohacer/Grupo Editor Latinoamericano.

CORIGLIANO, Francisco. La dimensión multilateral de las relaciones entre Argentina y Estados Unidos durante la década de 1990: el ingreso del paradigma de "relaciones especiales". In: C. Escudé (ed.) Historia General de las Relaciones Exteriores de la República Argentina - Tomo XV - Las 'Relaciones Carnales', los vínculos políticos con las grandes potencias 1989-2000. Cap.2, p.209-377. Buenos Aires: Nuevohacer/Grupo Editor Latinoamericano, 2003b, p.209-377.

CORTES, Maria Julieta. Brasil en la Política Exterior Argentina de los Noventa. Encuentre Veinte Años de Política Exterior en Democracia, 2003. La Plata. Anais, La Plata, CERPI, 2003, p.1-20. Disponível em: <http://www.iri.edu.ar/publicaciones_iri/IRI\%20COMPLETO\%20-\%20Publicaciones-V05/CD-\%20Cerpi/Inicio.htm>.Acesso em:29 jun. 2020.

ESCUDÉ, Carlos. Realismo periférico: fundamentos para la nueva política exterior argentina. Barcelona: Planeta, 1992.

ESCUDÉ, Carlos. Principios de Realismo Periférico: Una Teoria Argentina y su vigencia ante el Ascenso de China. Buenos Aires: Lumiere, 2012.

ESCUDÉ, Carlos. Entrevista. Buenos Aires, 24/10/2017.

GRONDONA, Mariano, Países al borde de un ataque de celos. La Nación, Buenos Aires, 24/08/1997. Disponível em: <https://www.lanacion.com.ar/75476-paises-al-borde-de-un-ataque-de-celos>. Acesso em: 24 abr. 2020.

HUNTINGTON, Samuel. The Lonely Superpower. Foreign Affairs, Washington, v.78, n.2, p.35-49, 1999.

LA NACIÓN. Elogios de Clinton hacia la economía argentina. La Nación, Buenos Aires, 09/09/1997a. Disponível em: <https://www.lanacion.com.ar/76481-elogios-de-clinton-hacia-la-economia-argentina>. Acesso em: 23 abr. 2020.

LA NACIÓN. Lo que deja la visita de Clinton. La Nación, Buenos Aires, 19/10/1997b. Disponível em <http://www.lanacion.com.ar/79070-lo-que-deja-la-visita-de-clinton.>. Acesso em: 23 abr. 2020.

LA NACIÓN. En la ONU, Menem volvió a desafiar a Brasil, La Nación, Buenos Aires, 22/09/1999. Disponível em: <https://www.lanacion.com.ar/politica/en-la-onu-menem-volvio-a-desafiar-a-brasil-nid154430>. Acesso em: 23 abr. 2020. 
LA NACIÓN. Herrera Vegas se despide de Brasil. La Nación, Buenos Aires, 07/02/2000. Disponível em: <http://www.lanacion.com.ar/4434-herrera-vegas-se-despide-de-brasil>. Acesso em: 23 abr. 2020.

LAMPREIA, Luiz Felipe. A reforma do Conselho de Segurança. Folha de São Paulo, São Paulo, 31/12/1997a. Disponível em: <https://folha.uol.com.br/fsp/opiniao/fz310808.htm>. Acesso em: 23 abr. 2020.

LAMPREIA, Luiz Felipe. Discurso do chanceler Luiz Felipe Lampreia na AGNU 1996. In: SEIXAS CORREA, Luiz F. (org), O Brasil nas Nações Unidas 1946-2006. Cap.1996, p.607-620. Brasília: FUNAG, 2007b.

LAMPREIA, Luiz Felipe. Luiz Felipe Lampreia (depoimento, 2008). Rio de Janeiro: CPDOC, 2010.

LINS, Carlos Eduardo L. da. Brasil critica opção argentina por Otan. Folha de São Paulo, São Paulo, 10/07/1999. Disponível em: $<$ https://www1.folha.uol.com.br/fsp/mundo/ft10079901.htm>. Acesso em: 23 abr. 2020.

LOHLÉ, Juan Pablo. Entrevista. Buenos Aires, 26/09/2017.

MELLO E SILVA, Alexandra. O Brasil no continente e no mundo: atores e imagens na política externa brasileira contemporânea. Estudos Históricos Rio de Janeiro, v.8 n.15, p.95-118, 1995.

PETRELLA, Fernando. Entrevista. Buenos Aires, 09/10/2017.

PICAZO, María Victoria. Argentina-EEUU: Balance de la Alianza Extra-OTAN. In: Congreso en Relaciones Internacionales, II, 2004. La Plata. Paper.

REFICCO, Ezequiel. Argentina como aliado extra-OTAN de los EEUU: Los Factores detrás de la Alianza. CIDOB Afers Internacionals, Barcelona, n. 42, p.79-97, 1998.

RUSSELL, Roberto. Los Ejes Estructurantes de la Política Exterior Argentina. Buenos Aires: FLACSO, 1994.

RUSSELL, Roberto. Argentina 1910-2010 Balance del siglo. Buenos Aires: Taurus, 2010.

RUSSELL, Roberto; NORDEN, Deborah. The United States and Argentina. Changing Relations in a Changing World. New York: Routledge: 2002.

RUSSELL, Roberto; TOKATLIAN, Juan G. El lugar de Brasil en la política exterior argentina. Buenos Aires: Fondo de Cultura Económica, 2003

RUSSELL, Roberto; TOKATLIAN, Juan G. Percepciones Argentinas de Brasil: Ambivalencias y Expectativas. Plataforma Democrática, 2011. Disponível em:

$<$ http://www.plataformademocratica.org/Arquivos/Plataforma_Democratica_Working_Paper_19_2011_Espanhol.pdf $>$. Acesso em: 23 abr. 2020 .

SALOMON, Marta. FHC ironiza acordo entre Argentina e EUA Folha de São Paulo, São Paulo, 23/08/1997. Disponível em: $<$ http://www1.folha.uol.com.br/fsp/brasil/fc230824.htm. Acesso em 23/04/2020>. Acesso em: 23 abr. 2020.

SARAIVA, Miriam G. Encontros e desencontros: o lugar da Argentina na política externa brasileira. Belo Horizonte, Fino Traço Editora, 2012.

SARNEY, José. Pronunciamento de José Sarney. Atividade Legislativa/Senado Federal, 20/ago./1997. Disponível em: <https://www25.senado.leg.br/web/atividade/pronunciamentos/-/p/texto/211427>. Acesso em: 26 abr. 2020.

SEIXAS CORREAA, Luiz Felipe de. Entrevista. Rio de Janeiro, 17/01/2018.

SOLIANI, André; ROSSI, Clóvis. Argentina pede para entrar na OTAN. Folha de São Paulo, São Paulo, 09/09/1999. Disponível em: $<$ https://www1.folha.uol.com.br/fsp/mundo/ft09079901.htm>. Acesso em: 23 abr. 2020.

SPEKTOR, Matias. Dezoito Dias: Quando Lula e FHC se uniram para buscar o apoio de Bush. Rio de Janeiro: Objetiva, 2014.

TORRES, Sérgio. Cavallo defende vaga para o Brasil. Folha de São Paulo, São Paulo, 27/08/1997. Disponível em: <http://www1.folha.uol.com.br/fsp/brasil/fc270803.htm>. Acesso em: 23 abr. 2020.

\begin{tabular}{ll}
\hline Funçães de colaboração exercidas & \\
\hline Ariane Costa dos Santos & Metodologia; Validação; Investigação; Escrita (primeira redação); Escrita (revisão e edição); \\
Miriam Gomes Saraiva & Metodologia; Investigação; Escrita (revisão e edição);
\end{tabular}

